\title{
Some DADNE Embedded Push-Pull Type Structures - A DFT Study
}

\section{Lemi Türker}

Department of Chemistry, Middle East Technical University, Üniversiteler, Eskişehir Yolu No: 1, 06800 Çankaya/Ankara, Turkey; e-mail: lturker@gmail.com; lturker@metu.edu.tr

\section{Abstract}

\begin{abstract}
In the present study, some diaminodinitroethylene, (geminal (FOX-7) and cis-DADNE) embedded isomeric structures $\left(\mathrm{C}_{4} \mathrm{H}_{2} \mathrm{~N}_{4} \mathrm{O}_{6}\right)$ are considered. They are consisted of a five or a six-membered ring having DADNE moiety (linked across the amino groups of DADNE) and two exocyclic keto groups. The structures have been subjected to density functional treatment at the levels of B3LYP/6-31G(d,p) and $\omega$ B97X-D/6-31G(d,p). Some geometrical, quantum chemical, spectral and thermodynamic properties are obtained and discussed. Also bond dissociation energies for the scission of $\mathrm{C}-\mathrm{NO}_{2}$ bonds are calculated at the level of UB3LYP/6-311++G(d,p) and found that the DADNE embedded structures have less stable $\mathrm{C}-\mathrm{NO}_{2}$ bond as compared to FOX-7.
\end{abstract}

\section{Introduction}

In the presently considered structures one of the embedded subunits is FOX-7, $(1,1-$ diamino-2,2-dinitroethylene, geminal DADNE), which is also known as DADNE or DADE [1]. FOX-7 was synthesized in 1998 by the Swedish Defense Research Agency (FOI) [2, 3]. A short time later, its explosive potential was thoroughly investigated [418]. Another approach to its synthesis involves the nitration of 4,6-dihydroxy-2methylpyrimidine and then subsequent hydrolysis [19]. An isomer of FOX-7 is vicinal DADNE. Also trans DADNE is possible.

Received: March 10, 2019; Accepted: April 11, 2019

Keywords and phrases: FOX-7, DADNE, explosive, push-pull, oxygen balance, impact sensitivity, bond dissociation energy.

Copyright (C) 2019 Lemi Türker. This is an open access article distributed under the Creative Commons Attribution License, which permits unrestricted use, distribution, and reproduction in any medium, provided the original work is properly cited. 


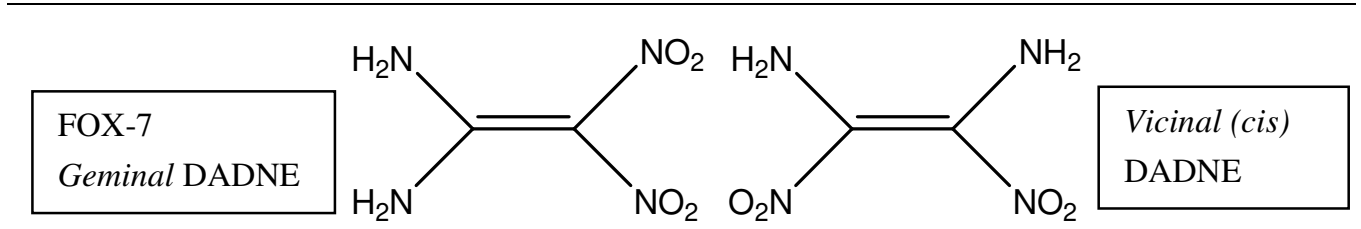

FOX-7 is a novel high-energy insensitive material having good thermal stability and low sensitivity. Although no structural resemblance exists among FOX-7, RDX and HMX they have the same $\mathrm{C} / \mathrm{H} / \mathrm{N} / \mathrm{O}$ ratio. However, in terms of impact, friction, and electrostatic discharge sensitivities FOX-7 is much less sensitive than RDX [20].

Although structure of FOX-7 is simple, it surprisingly exhibits diverse and abundant chemical reactivity because of the amino and nitro groups it has (including coordination reactions, nucleophilic substitutions, electrophilic addition reactions, salification reaction, acetylate reactions, oxidizing and reduction reactions, etc., [21, 22]).

FOX-7 is an attractive ingredient for application in high performance insensitive munition (IM) compliant explosive recipes. FOX-7 also possesses the ability of increasing the burning rate in propellants, thus it is of interest for high performance propellants [1].

FOX-7 possesses many polymorphic forms. It is known that the $\alpha$-form reversibly turns into $\beta$-form by heat treatment $[23,24]$. Also, at higher temperature, $\beta$-polymorph exhibits an irreversible conversion to $\gamma$-phase which decomposes at $504 \mathrm{~K}$ [23]. Its decomposition has been extensively investigated [25]. Also the effect of high pressure on the crystal structure of FOX-7 has been searched [26].

So far many FOX-7 based propellant formulations have been studied in order to obtain a reduced or minimum smoke producing composite propellant with inherent insensitive munition properties [27].

On the other hand, thermo chemical calculations have been reported indicating that PBX's based on FOX-7 and energetic binders could serve as a replacement of Comp-B. Even at rather low solid loadings, such as a plastic bound explosive based on FOX-7 and an energetic binder have been prepared, [28].

Various ground state properties of FOX-7 were calculated based on B3LYP/aug-ccpVDZ predictions [29]. The effects of nitration and epoxidation on ballistic properties of FOX-7 were also investigated within the realm of density functional theory (DFT) [30]. 
Laser ignitibility of FOX-7 was investigated in order to achieve the direct optical ignition of an insensitive explosive [31]. Also quite recently, some novel derivatives of FOX-7 (geminal DADNE) and their properties as energetic materials have been reported $[32,33]$.

In the present study, geminal or cis-DADNE embedded isomeric structures $\left(\mathrm{C}_{4} \mathrm{H}_{2} \mathrm{~N}_{4} \mathrm{O}_{6}\right)$ and some of their tautomeric forms are considered within the constraints of density functional theory (DFT).

\section{Method of Calculation}

Optimizations of all the structures leading to energy minima were initially achieved by using MM2 method and then by semi-empirical PM3 self-consistent fields molecular orbital (SCF MO) method [34, 35] at the restricted level [36, 37]. Subsequent optimizations were achieved at Hartree-Fock level using various basis sets hierarchically. Then, the subsequent optimizations were managed within the framework of density functional theory [38, 39], finally at the level of RB3LYP /6-31G(d,p) [36] and $\omega B 97 X-$ D/ 6-31G(d,p) [40, 41]. The exchange term of B3LYP consists of hybrid Hartree-Fock (HF) and local spin density (LSD) exchange functions with Becke's gradient correlation to LSD exchange [39, 42]. Note that the correlation term of B3LYP consists of the Vosko, Wilk, Nusair (VWN3) local correlation functional [43] and Lee, Yang, Parr (LYP) correlation correction functional [44]. Also note that $\omega$ B97XD functional provides excellent geometries and energies. It has high HF percentage $(\omega \mathrm{B} 97 \mathrm{XD}$ is a long-range corrected functional), which helps mitigate the self-interaction error and the difficult excitation energies required for charge transfer reactions [40, 41].

The bond dissociation energy calculations have been done at the level of UB3LYP/6$311++G(d, p)$ level. For all the systems considered, the vibrational analyses were also done. The total electronic energies are corrected for the zero point vibrational energy (ZPE). The stationary points to energy minima were proved in all the cases by calculation of the second derivatives of energy with respect to the atom coordinates. The normal mode analysis for each structure yielded no imaginary frequencies for the $3 \mathrm{~N}-6$ vibrational degrees of freedom, where $N$ is the number of atoms in the system. This indicates that the structure of each molecule corresponds to at least a local minimum on the potential energy surface. All these calculations were done by using the Spartan 06 package program [45]. In the present treatment the calculations (except the bond 
dissociation energy calculations) have been performed at the levels of B3LYP/6$31 \mathrm{G}(\mathrm{d}, \mathrm{p})$ and $\omega \mathrm{B} 97 \mathrm{X}-\mathrm{D} / 6-31 \mathrm{G}(\mathrm{d}, \mathrm{p})$. Note that in these two groups of calculations the basis set is common but the functionals are different.

\section{Results and Discussion}

\subsection{Structures and some properties}

In isomeric structures I and II $\left(\mathrm{C}_{4} \mathrm{H}_{2} \mathrm{~N}_{4} \mathrm{O}_{6}, \mathrm{MW}: 202 \mathrm{~g}\right)$, geminal (FOX-7) and vicinal (cis)-diaminodinitroethylene), are respectively present as subunits. These structures have the oxygen balance (OB) value of -23.76 compared to -21.62 of FOX-7. They are supposed to be obtainable from the parent DADNE compounds by means of oxalyl chloride treatment.
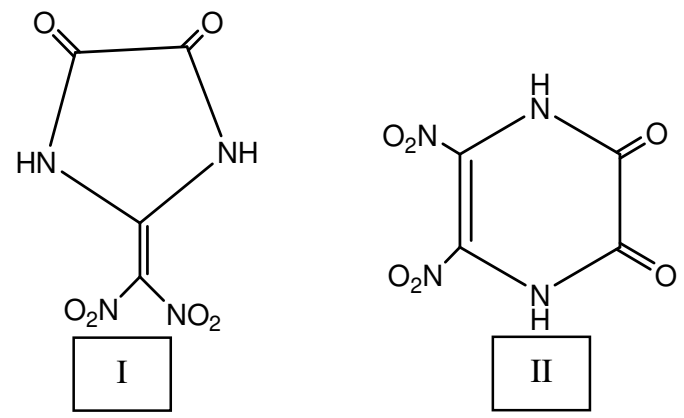

Figure 1 shows the optimized structures I and II as well as 1,3-tautomers of them. The figure also displays the directions of the dipole moment vectors. Structure II is different from the others because the direction of dipole moment vector is from the side of nitro groups to the six-membered ring. The same behavior is displayed in the case of $\omega \mathrm{B} 97 \mathrm{X}-\mathrm{D} / 6-31 \mathrm{G}(\mathrm{d}, \mathrm{p})$ level of optimization (Figure 2). In geminal and vicinal(cis) DADNE the direction of dipole moment is from site of amino groups to the site of nitro groups. This is a normally expected push-pull behavior. Therefore, the situation in structure-II is odd. It seems that the amino groups in II are strongly under the effect of carbonyl groups and this effect might be assisted by the topology of the six-membered ring.

Figure 3 shows the bond lengths of the structures considered. The both level of calculations yield similar results for the bond lengths and the values are reasonable. 

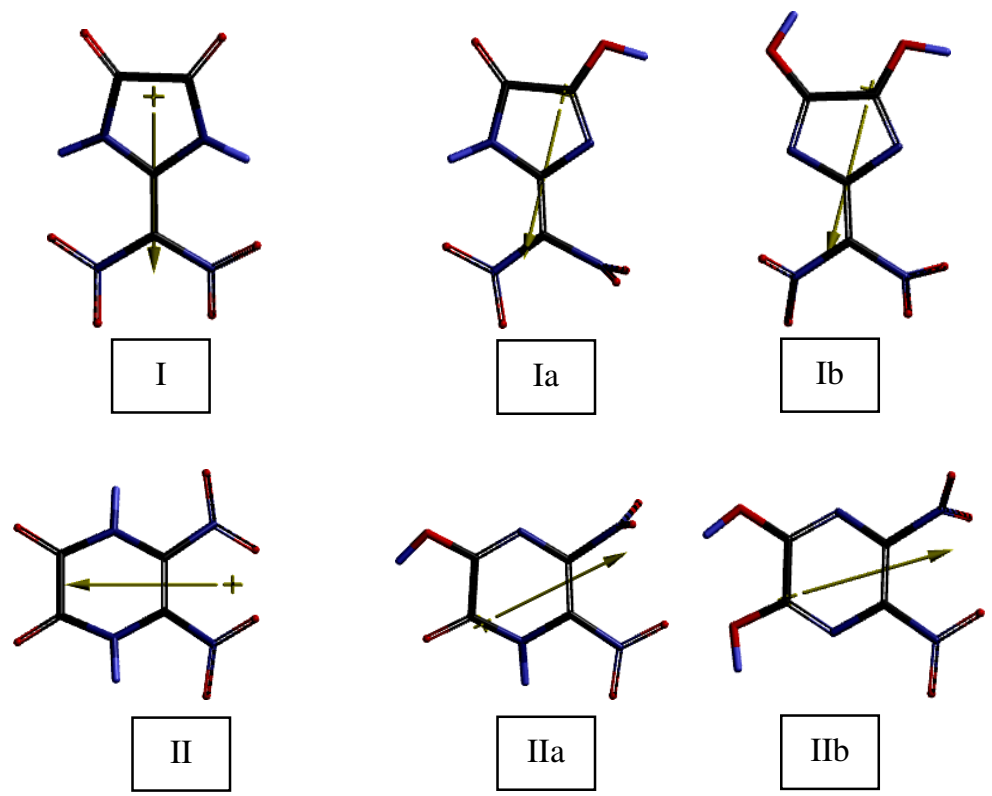

Figure 1. Optimized structures of the molecules considered (B3LYP/6-31G(d,p)).
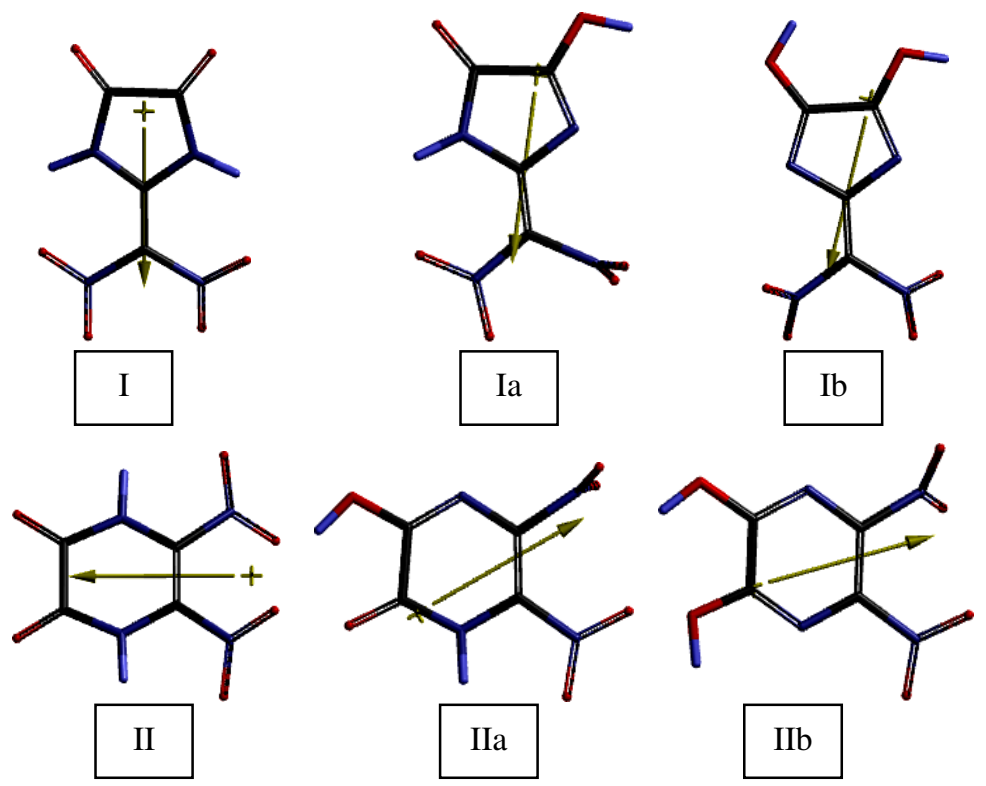

Figure 2. Optimized structures of the molecules considered $(\omega \mathrm{B} 97 \mathrm{X}-\mathrm{D} / 6-31 \mathrm{G}(\mathrm{d}, \mathrm{p}))$. 

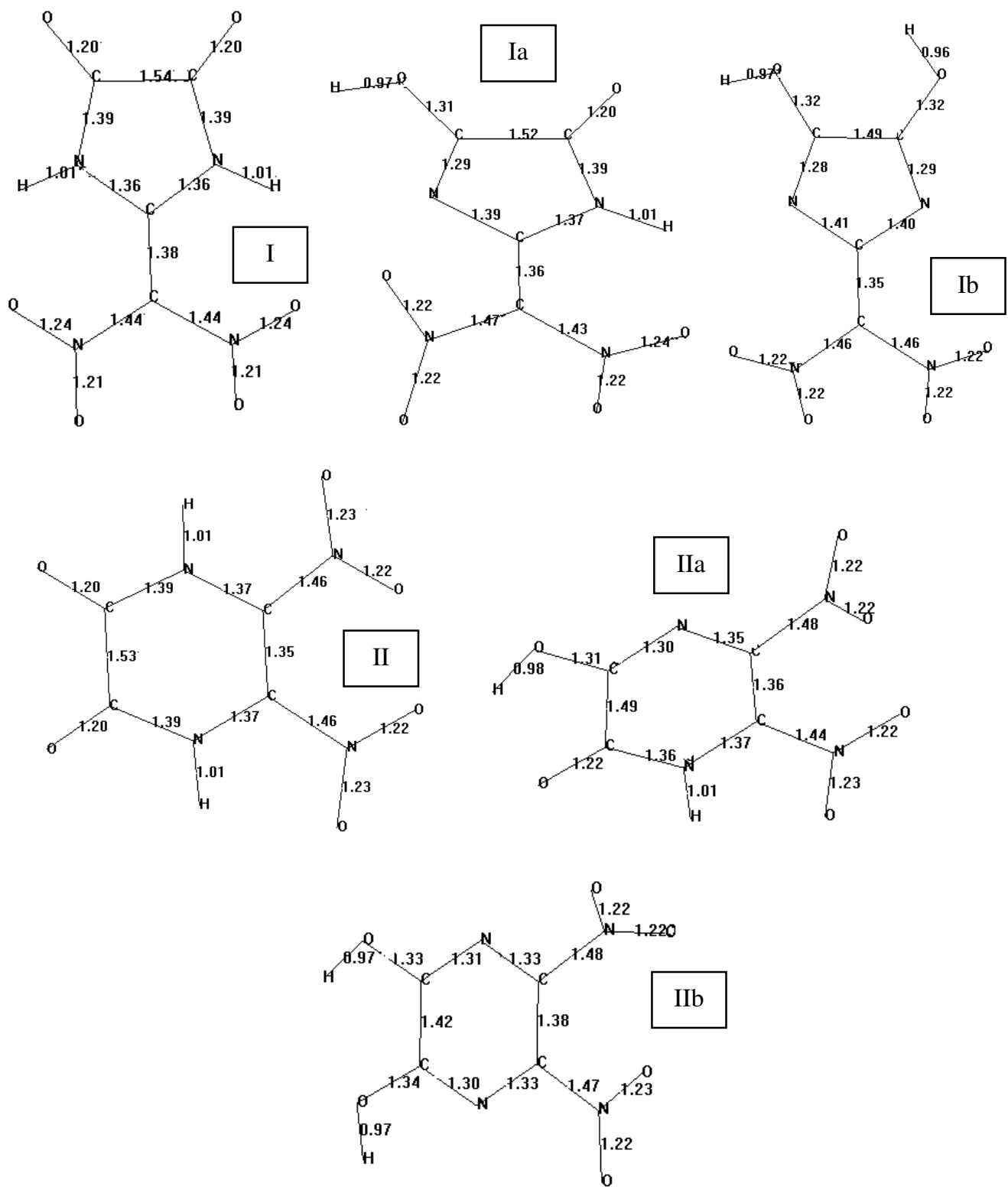

Figure 3. Bond lengths $(\AA)$ of the structures (B3LYP/6-31G(d,p)).

In Table 1 some properties of the structures are tabulated. Note that the tautomers of I (Ia, Ib) and II (IIa, IIb) have less heat of formation values as compared to the parent 
structures. Also, structure- $\mathrm{I}$ is characterized with more negative $\Delta \mathrm{H}_{\mathrm{f}}^{\circ}$ as compared to structure-II.

Table 1. Some properties of the structures considered.

\begin{tabular}{lcccccc}
\hline \multicolumn{7}{c}{ Structures } \\
\hline Property & I & Ia & Ib & II & IIa & Ilb \\
\hline Area $\left(\AA^{2}\right)$ & 172.25 & 177.51 & 179.92 & 172.95 & 173.01 & 174.59 \\
& $(171.54)$ & $(176.62)$ & $(179.00)$ & $(172.32)$ & $(172.13)$ & $(173.58)$ \\
Volume $\left(\AA^{3}\right)$ & 144.42 & 145.13 & 145.56 & 144.68 & 143.70 & 143.89 \\
& $(143.82)$ & $(144.49)$ & $(144.88)$ & $(144.09)$ & $(143.04)$ & $(143.22)$ \\
Ovality & 1.29 & 1.33 & 1.34 & 1.30 & 1.30 & 1.31 \\
& $(1.29)$ & $(1.33)$ & $(1.34)$ & $(1.30)$ & $(1.30)$ & $(1.31)$ \\
Polarizability & 52.07 & 52.25 & 52.27 & 52.32 & 52.14 & 51.98 \\
& $(51.10)$ & $(51.29)$ & $(51.29)$ & $(51.34)$ & $(51.17)$ & $(50.99)$ \\
$\log \mathrm{P}$ & -0.36 & 0.51 & 1.38 & -0.36 & 0.51 & 1.38 \\
& $(-0.36)$ & $(0.51)$ & $(1.38)$ & $(-0.36)$ & $(0.51)$ & $(1.38)$ \\
$\Delta \mathrm{H}_{\mathrm{f}}^{\circ}(\mathrm{kJ} / \mathrm{mol})$ & -244.842 & -159.175 & -49.124 & -188.251 & -169.079 & -184.884 \\
\hline
\end{tabular}

B3LYP/6-31G(d,p) level; $\omega$ B97X-D/6-31G(d,p) level of calculations are in parenthesis. $\Delta \mathrm{H}_{\mathrm{f}}^{\circ}$ values from PM3//B3LYP/6-31G(d,p) level.

Figure 4 shows the electrostatic charges (ESP) for atoms of the structures. Note that the ESP charges are obtained by the program based on a numerical method that generates charges that reproduce the electrostatic potential field from the entire wavefunction [45]. The charge distribution in I or II is highly symmetrical. In the case of tautomers, the symmetry is lost which affects the charge distribution, e.g., the fulvene system in Ib has unsymmetrical charge distribution, even at $\mathrm{NO}_{2}$ groups which are farthest away from the OH substituents. 

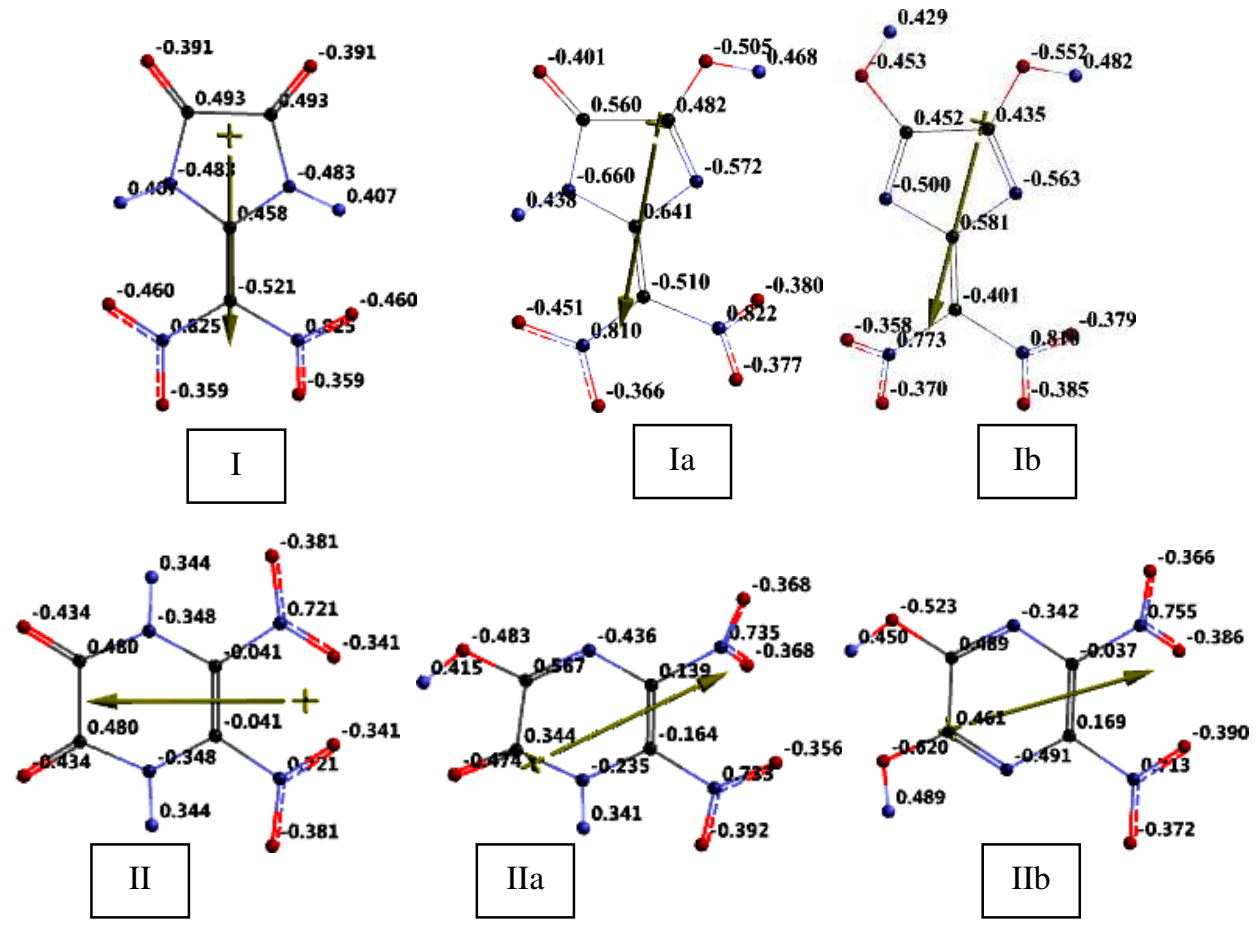

Figure 4. Electrostatic charges (ESP) on the atoms of the structures considered $(\omega \mathrm{B} 97 \mathrm{X}-$ $\mathrm{D} / 6-31 \mathrm{G}(\mathrm{d}, \mathrm{p})$ level$)$.

\subsection{Energies and stabilities}

Table 2 shows the total electronic energy (E), zero point vibrational energy (ZPE) and the corrected total electronic energy $\left(\mathrm{E}_{\mathrm{c}}\right)$ for the structures considered. Note that these structures are isomeric. Therefore, their $E_{c}$ values can reflect their relative stabilities in someway. The stability order is I $>\mathrm{IIa}>\mathrm{II}>\mathrm{IIb}>\mathrm{Ia}>\mathrm{Ib}(\mathrm{B} 3 \mathrm{LYP} / 6-31 \mathrm{G}(\mathrm{d}, \mathrm{p})$ and $\mathrm{I}>\mathrm{II} \mathrm{a}>\mathrm{II} \mathrm{b}>\mathrm{II}>\mathrm{Ia}>\mathrm{Ib}(\omega \mathrm{B} 97 \mathrm{X}-\mathrm{D} / 6-31 \mathrm{G}(\mathrm{d}, \mathrm{p}))$ (reverse order of $\mathrm{E}_{\mathrm{c}}$ values). Structure-I appears to be more stable than structure-II, even though it has a five-membered ring which is expected to have more ring strain compared to a six-membered ring.

\subsection{IR spectra}

Figure 5 shows the IR spectra of the structures considered. Structures I and II possess the N-H stretching peaks at $3567 \mathrm{~cm}^{-1}$ and $3557 \mathrm{~cm}^{-1}$, respectively. At $1886 \mathrm{~cm}^{-1}$ 
Table 2. Various energies of the systems considered.

\begin{tabular}{cccc}
\hline Structure & $\mathbf{E}$ & $\mathbf{Z P E}$ & $\mathbf{E}_{\mathbf{c}}$ \\
\hline I & -2162825.57 & 237.53 & -2162588.04 \\
& $(-2162138.48)$ & $(243.98)$ & $(-2162626.44)$ \\
Ia & -2162760.48 & 237.02 & -2162523.46 \\
& $(-2162070.77)$ & $(243.33)$ & $(-2162314.1)$ \\
Ib & -2162660.23 & 235.18 & -2162425.05 \\
& $(-2161969.86)$ & $(241.74)$ & $(-2162211.6)$ \\
II & -2162782.97 & 237.61 & -2162545.36 \\
& $(-2162093.22)$ & $(243.98)$ & $(-2162337.2)$ \\
IIa & -2162787.19 & 238.45 & -2162548.74 \\
& $(-2162096.82)$ & $(245.06)$ & $(-2162586.94)$ \\
IIb & -2162766.14 & 236.72 & -2162529.42 \\
& $(-2162078.34)$ & $(243.35)$ & $(-2162529.42)$ \\
\hline
\end{tabular}

Energies in kJ/mol. B3LYP/6-31G(d,p) level; $\omega$ B97X-D/6-31G(d,p) level of calculations are in parenthesis.

asymmetrical $\mathrm{C}=\mathrm{O}$ stretching of I and at $1840 \mathrm{~cm}^{-1}$ symmetrical stretching of II occur. The $\mathrm{C}=\mathrm{C}$ bond stretches at $1670 \mathrm{~cm}^{-1}$ and $1652 \mathrm{~cm}^{-1}$ in structures I and II, respectively. In the case of tautomers, O-H stretching occurs at $3736 \mathrm{~cm}^{-1}$ and $3588 \mathrm{~cm}^{-1}$ in structures Ia and IIa, respectively. The $\mathrm{C}=\mathrm{O}$ bond vibrates at $1872 \mathrm{~cm}^{-1}$ in structure-I. The corresponding value is $1875 \mathrm{~cm}^{-1}$ for structure-II. The $\mathrm{C}=\mathrm{C}$ vibration in $\mathrm{I}$ is coupled with the skeletal breathing of the ring at $1674 \mathrm{~cm}^{-1}$ whereas it occurs at $1687 \mathrm{~cm}^{-1}$ in II. In the case of structures $-\mathrm{Ib}$ and $-\mathrm{IIb}$, the $\mathrm{O}-\mathrm{H}$ stretchings occur in the region of 3792-3760 $\mathrm{cm}^{-1}$. 

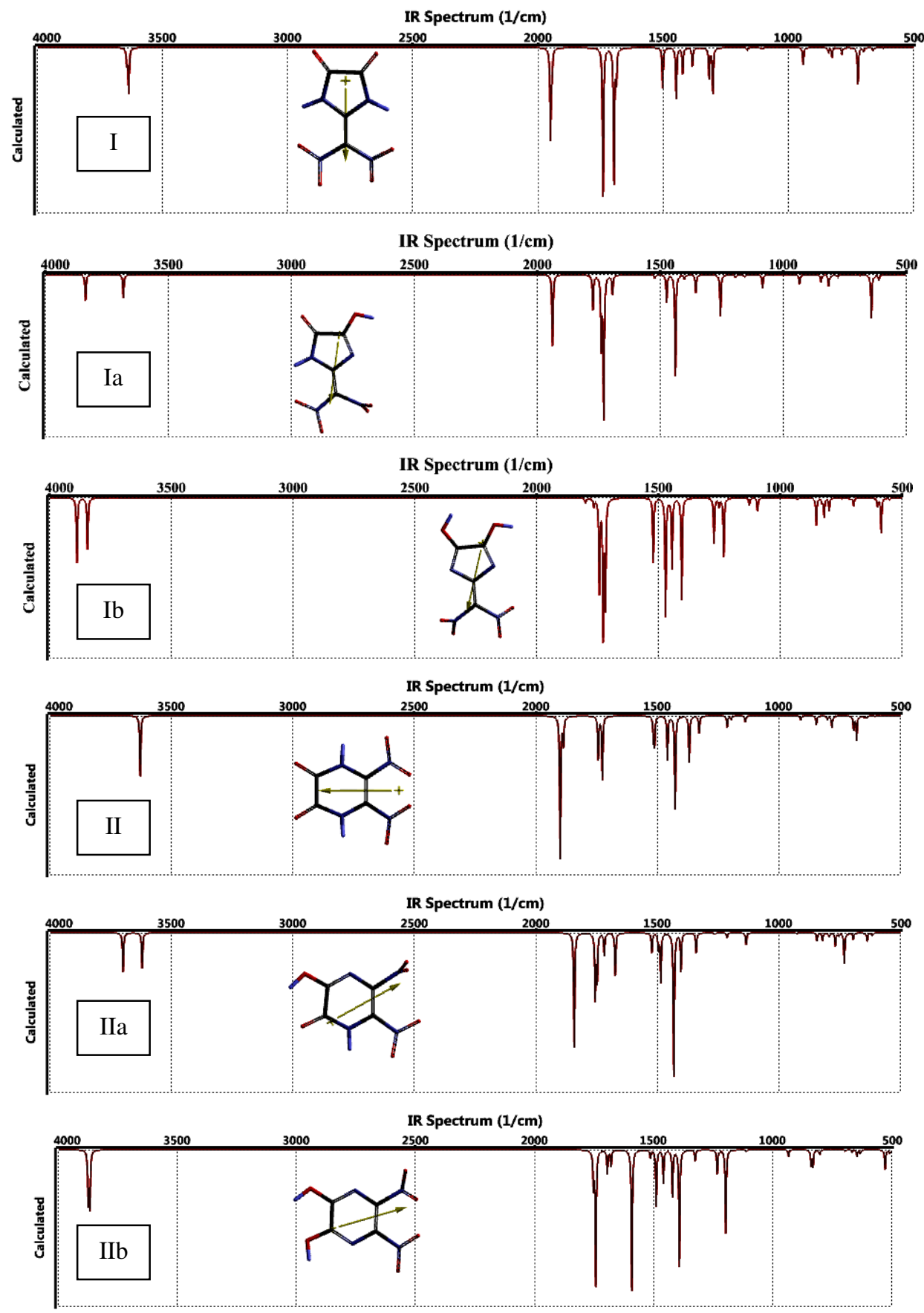

Figure 5. IR spectra of the structures considered ( $\omega B 97 X-D / 6-31 G(d, p)$ level). 


\subsection{Thermodynamical properties}

Table 3 contains some thermodynamical properties of the structures according to the level of calculations have been performed. The $\mathrm{H}^{\circ}$ and $\mathrm{G}^{\circ}$ values follow the order of $\mathrm{I}<\mathrm{II} a \mathrm{II}<\mathrm{Il} b<\mathrm{Ia}<\mathrm{Ib}$. The variations of $\mathrm{H}^{\circ}$ among these structures arise from the variations in their internal energies $(\mathrm{U})$ and molar volumes $(\mathrm{V})$ by $\mathrm{H}^{\circ}=\mathrm{U}+\mathrm{PV}[46]$. As for the variations in $G^{\circ}$ values also the entropy factor contributes as $G^{\circ}=H^{\circ}+\mathrm{TS}^{\circ}$.

Table 3. Some thermochemical properties of the structures considered.

\begin{tabular}{ccccc}
\hline Structures & \multicolumn{4}{c}{ Property } \\
\hline & $\mathrm{H}^{\circ}(\mathrm{kJ} / \mathrm{mol})$ & $\mathrm{S}^{\circ}(\mathrm{J} / \mathrm{mol})$ & $\mathrm{G}^{\circ}(\mathrm{kJ} / \mathrm{mol})$ & $\mathrm{Cv}(\mathrm{J} / \mathrm{mol})$ \\
\hline I & -2162579.68 & 405.73 & -2162700.65 & 128.63 \\
& $(-2161886.46)$ & $(404.04)$ & $(-2162006.92)$ & $(126.57)$ \\
Ia & -2162514.814 & 414.25 & -2162638.324 & 129.72 \\
& $(-2161819.091)$ & $(412.57)$ & $(-2161942.103)$ & $(127.90)$ \\
Ib & -2162415.808 & 417.05 & -2162540.155 & 130.18 \\
& $(-2161719.224)$ & $(414.96)$ & $(-2161842.944)$ & $(128.33)$ \\
II & -2162536.83 & 412.62 & -2162659.85 & 129.56 \\
& $(-2161840.93)$ & $(410.89)$ & $(-2161963.44)$ & $(127.92)$ \\
IIa & -2162540.47 & 410.95 & -2162663.00 & 128.45 \\
& $(-2161843.82)$ & $(408.83)$ & $(-2161965.72)$ & $(126.56)$ \\
& -2162520.61 & 413.62 & -2162643.94 & 130.10 \\
IIb & $(-2161826.56)$ & $(411.13)$ & $(-2161949.14)$ & $(128.00)$ \\
\hline
\end{tabular}

B3LYP/6-31G(d,p) level; $\omega$ B97X-D/6-31G(d,p) level of calculations are in parenthesis.

\subsection{Molecular orbital energies}

Figure 6 shows some of the molecular orbital energy levels of the structures considered. As seen in the figure an isomeric variation in the embedded DADNE moiety makes structures I and II to have highly different molecular orbital energy spectra. The 
NEXTHOMO level of structure-I is more closely spaced to its HOMO as compared to the case of its tautomers Ia and Ib. A similar case is valid for the NEXTLUMO and LUMO levels. As for the case of structure-II and its tautomers the NEXTHOMO of II is closer to the HOMO as they are in the tautomers. On the other hand, structure-IIb has noticeable closely spaced LUMO and NEXTLUMO levels.
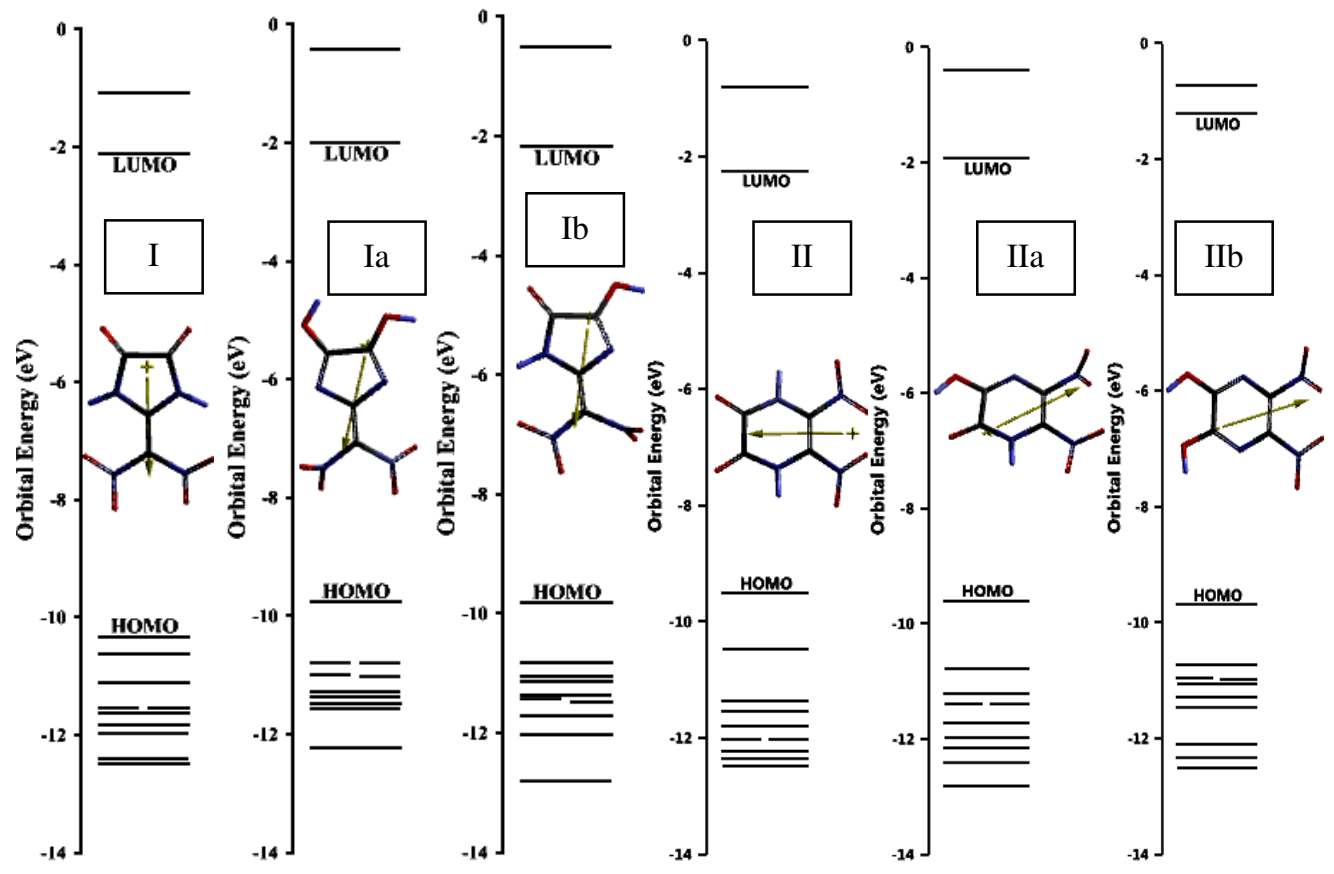

Figure 6. Some of the molecular orbital energy levels of the structures considered $(\omega \mathrm{B} 97 \mathrm{X}-\mathrm{D} / 6-31 \mathrm{G}(\mathrm{d}, \mathrm{p}))$.

Table 4 includes the HOMO, LUMO energies and the interfrontier molecular orbital energy gaps ( $\left.\Delta \varepsilon=\varepsilon_{\mathrm{LUMO}}-\varepsilon_{\mathrm{HOMO}}\right)$. The HOMO energy order is $\mathrm{I}<\mathrm{Ia}<\mathrm{Ib} \sim \mathrm{Il} b<\mathrm{IIa}<\mathrm{II}$. The LUMO energies follow the order of II $<\mathrm{Ia}<\mathrm{I}<\mathrm{Ib}<\mathrm{IIa}<\mathrm{III}$. Consequently, the order of $\Delta \varepsilon$ values become IIb $>\mathrm{I}>\mathrm{Ib}>\mathrm{Ia}>\mathrm{IIa}>\mathrm{II}(\mathrm{B} 3 \mathrm{LYP} / 6-31 \mathrm{G}(\mathrm{d}, \mathrm{p})$. At the level of $\omega \mathrm{B} 97 \mathrm{X}-\mathrm{D} / 6-$ $31 \mathrm{G}(\mathrm{d}, \mathrm{p})$ the same order of $\Delta \varepsilon$ values holds except IIa>Ia. When the values for structurally main isomers, I and II, are compared, one observes that the six-membered ring having isomer (II) has higher HOMO but lower LUMO energy as compared to the five-membered ring owner isomer (Ia), so going from five to six-membered ring $\Delta \varepsilon$ decreases. 
Table 4. The HOMO, LUMO energies and $\Delta \varepsilon$ values.

\begin{tabular}{lccc}
\hline Structure & HOMO & LUMO & $\Delta \varepsilon$ \\
\hline I & -799.15 & -381.93 & 417.22 \\
& -996.69 & -203.48 & 793.21 \\
Ia & -751.69 & -384.64 & 367.05 \\
& -947.86 & -209.63 & 738.23 \\
Ib & -741.75 & -368.91 & 372.84 \\
& -942.18 & -191.88 & 750.3 \\
II & -726.53 & -403.55 & 322.98 \\
& -917.75 & -216.60 & 701.15 \\
IIa & -732.77 & -367.93 & 364.84 \\
& -926.55 & -186.77 & 739.78 \\
IIb & -741.12 & -308.31 & 432.81 \\
& -935.80 & -117.97 & 817.83 \\
\hline
\end{tabular}

Energies in $\mathrm{kJ} / \mathrm{mol}$. The first and second entries in each row stand for B3LYP/6$31 \mathrm{G}(\mathrm{d}, \mathrm{p})$ and $\omega \mathrm{B} 97 \mathrm{X}-\mathrm{D} / 6-31 \mathrm{G}(\mathrm{d}, \mathrm{p})$ level of calculations, respectively.

It has been reported that as the HOMO-LUMO energy gap $(\Delta \varepsilon)$ decreases, the explosive becomes more sensitive to impact [47-51]. Therefore, structure-II is expected to be more sensitive to impact stimulus than structure-I.

\subsection{UV-VIS spectra}

Figure 7 shows the UV-VIS spectra of the structures considered. As seen in the figure, structure-II absorbs at relatively higher UV region as compared to structure-I which has an exocyclic carbon-carbon double bond. The nitrogen atoms embedded in the five-membered ring of structure-I seem to be less willingly to denote electrons to ethylenic or carbonyl chromophore(s) in order to extend the conjugation, thus to cause a bathochromic effect (shift) to longer wavelenghts. This might be due to the presence of more ring strain present in the five-membered ring as compared to the six-membered ring of structure-II. Structure-II is characteristic because it does not have any shoulder albeit the fact that the others have. 

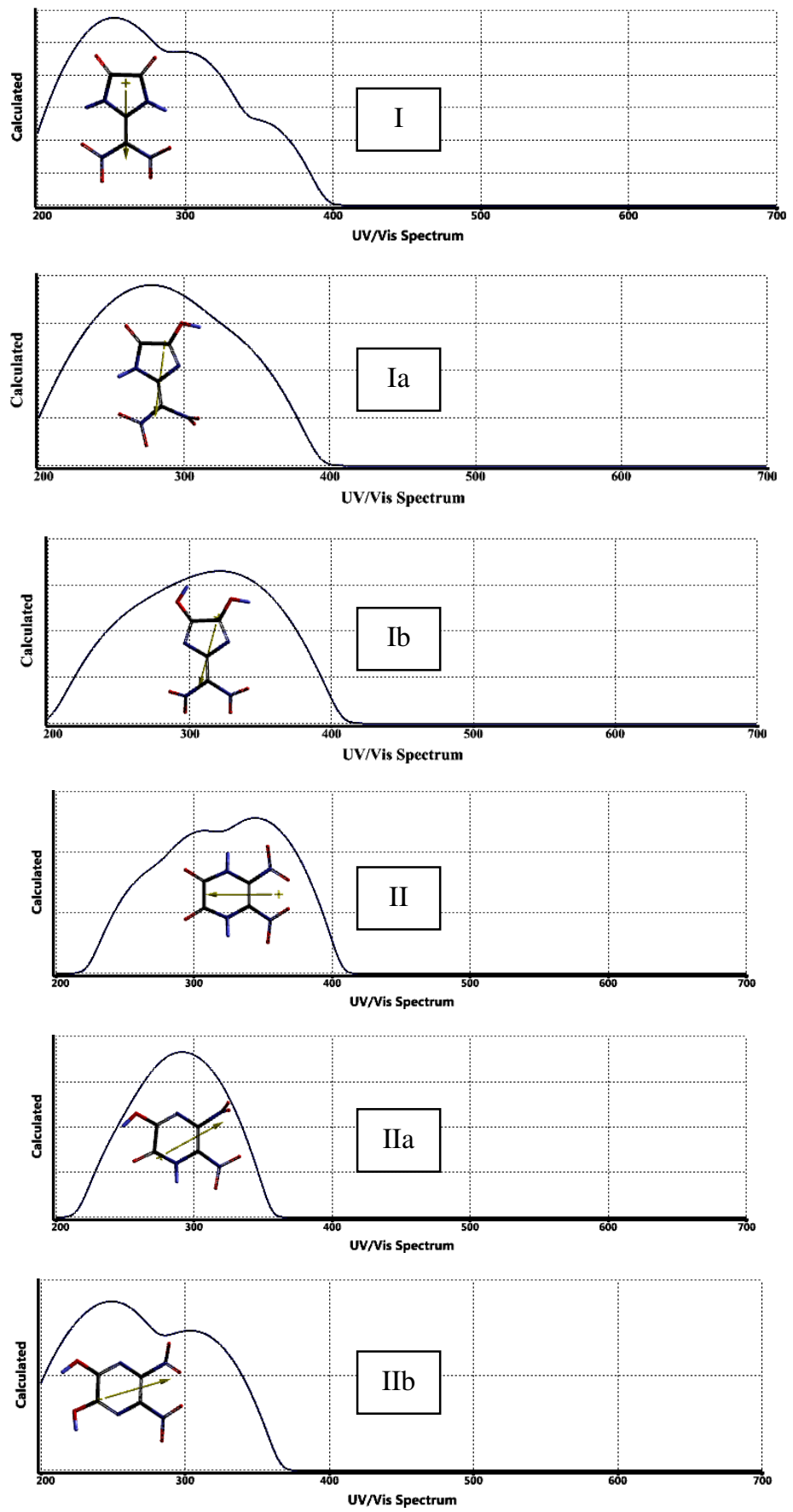

Figure 7. UV-VIS spectra of the structures considered ( $\omega B 97 X-D / 6-31 G(d, p)$ level). 
Figure 8 displays the electrostatic potential maps of the structures considered. In structures I and II, central part of them is characterized with some positive potential whereas various degree of negative potential reside on the keto-oxygens and nitrooxygens. In the tautomers, the negative potential regions spread over greater part of the structures at the expense of positive potential regions.
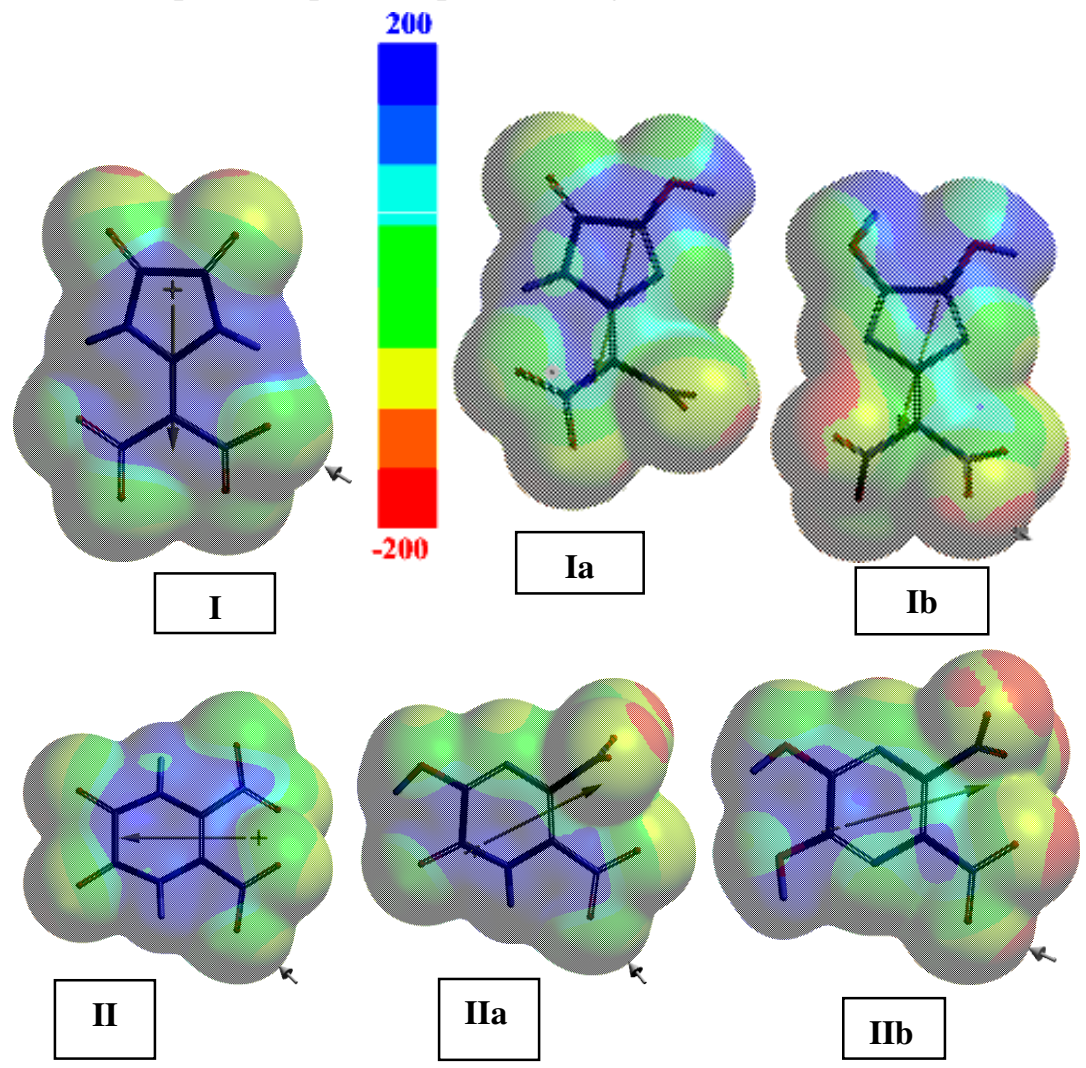

Figure 8. Electrostatic potential maps of the structures considered (B3LYP/6-31G(d,p)).

\subsection{Bond dissociation energies}

The sensitivity of an energetic material under different heat, impact, friction conditions may vary. Impact sensitivities of energetic compounds can be examined experimentally by physical tests, particularly drop height test. Additionally, there are theoretical methods for the computational determination of the impact sensitivity. Murray et al., [52] have indicated that there is an association between the bond dissociation energies (BDEs) of the nitro bonds and the electrostatic potentials on the molecular surfaces of some energetic molecules. In the literature there are several 
appreciated studies [53-56] on the homolytic BDE of the nitro compounds such as nitroaromatic and nitramine molecules. They have indicated that there is a parallel correlation between the BDE for the weakest nitro bond scission in the molecule and its impact sensitivity. The typical tendency is that the larger the homolytic BDE value for scission of nitro bond, the lower the sensitivity is.

Numerous experimental studies show that nitramine $\left(\mathrm{N}^{\left.-\mathrm{NO}_{2}\right)}\right.$ bond homolysis is the initial step in the thermal decomposition of hexahydro-1,3,5-trinitro-1,3,5-triazine (RDX) and other nitramines [57-61]. In the present study, in order to compare the $\mathrm{C}-\mathrm{NO}_{2}$ bond strengths of the compounds, homolytic bond dissociation energy (BDE) calculations considering the removal of nitrogen dioxide moiety from the parent structures were performed at UB3LYP/6-311++G(d,p) level of theory. A rather high basis set has been employed to minimize the basis set superposition error (BSSE) because it would vanish in the limit using a complete set for each system involved in BDE calculations [62]. The expressions for the homolysis of $\mathrm{R}-\mathrm{NO}_{2}$ bond and for calculating its homolytic BDE are shown as follows,

$$
\begin{aligned}
& \mathrm{R}-\mathrm{NO}_{2}(\mathrm{~g}) \rightarrow \mathrm{R}^{\prime}(\mathrm{g})+\mathrm{NO}_{2}^{\prime}(\mathrm{g}) \\
& \mathrm{BDE}\left(\mathrm{R}-\mathrm{NO}_{2}\right)=\left[\mathrm{E}_{\mathrm{R}}^{\cdot}+\mathrm{E}_{\mathrm{NO}_{2}}^{\cdot}\right]-\mathrm{E}_{\left(\mathrm{R}-\mathrm{NO}_{2}\right)}
\end{aligned}
$$

where $\mathrm{R}-\mathrm{NO}_{2}$ denotes the neutral molecule and $\mathrm{R}^{\prime}$ and $\mathrm{NO}_{2}$ stand for the corresponding product radicals after the bond dissociation. The $\operatorname{BDE}\left(\mathrm{R}-\mathrm{NO}_{2}\right)$ is the bond dissociation energy of the bond $\mathrm{R}-\mathrm{NO}_{2}$ whereas $\mathrm{E}\left(\mathrm{R}-\mathrm{NO}_{2}\right), \mathrm{E}\left(\mathrm{R}^{\prime}\right)$ and $\mathrm{E}\left(\mathrm{NO}_{2}\right)$ are the zero-point energy corrected total energies of the parent compound and the corresponding radicals, respectively [63-65].

Table 5 shows various energies of the systems considered in bond dissociation energy calculations. At UB3LYP/6-311++G(d,p) level of calculations structure-I appears to be more stable than structure-II (same as the results of previous level of calculations). The radicals from structures-I and II possess stability order of $I(R)>I I(R)$. Figure 9 shows the optimized structures of these radicals.

The bond dissociation energies of FOX-7 and structures I and II are shown in Table 6. As seen there, the bond dissociation energies follow the order of II $<$ I $<$ FOX-7, 

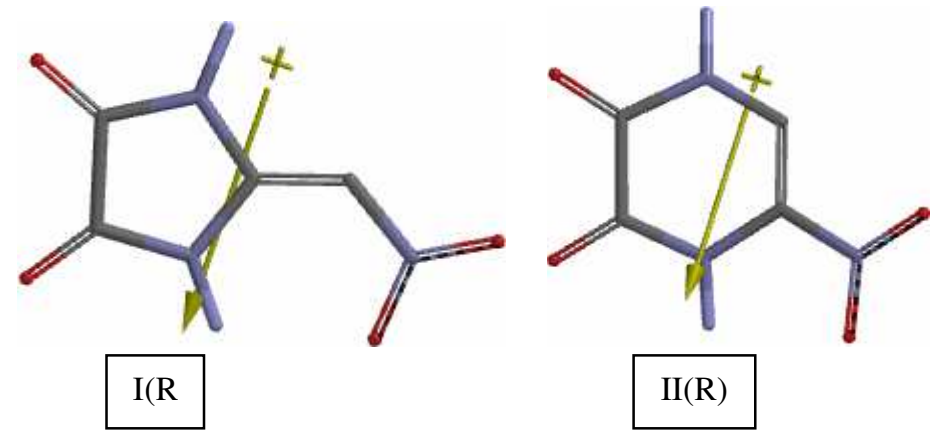

Figure 9. Optimized structures of radicals $I(R)$ and II(R).

Table 5. Various energies of the systems considered in bond dissociation energy calculations.

\begin{tabular}{cccc}
\hline Structure & $\mathbf{E}$ & $\mathbf{Z P E}$ & $\mathbf{E}_{\mathbf{c}}$ \\
\hline FOX-7 & -1571382.65 & 240.80 & -1571141.85 \\
FOX-7 (R) & -1032511.29 & 199.89 & -1032311.4 \\
I & -2163466.62 & 235.99 & -2163230.63 \\
I(R) & -1624613.13 & 195.87 & -1624417.26 \\
II & -2163424.44 & 235.50 & -2163188.94 \\
II(R) & -1624600.64 & 196.26 & -1624404.38 \\
\hline $\mathrm{NO}_{2}(\mathrm{R})$ & -538597.24 & 23.03 & -538574.21 \\
\hline
\end{tabular}

Energies in kJ/mol. UB3LYP/6-311++G(d,p) level.

namely FOX-7 structure is less likely to undergo $\mathrm{C}-\mathrm{NO}_{2}$ bond cleavage by certain stimulus. As pointed out in section 3.2, structure-I is over all more stable than structure-II and its $\mathrm{C}-\mathrm{NO}_{2}$ bond is more stable than the respective bond of structure-II.

Table 6. The C-NO${ }_{2}$ bond dissociation energies of some of the structures considered.

\begin{tabular}{cc}
\hline Structure & BDE \\
\hline FOX-7 & 256.24 \\
I & 239.16 \\
II & 210.35 \\
\hline
\end{tabular}

Energies in $\mathrm{kJ} / \mathrm{mol}$. UB3LYP/6-311++G(d,p) level. 


\section{Conclusion}

In the present study, some diaminodinitroethylene, (geminal and cis-DADNE) moiety embedded isomeric structures and some of their tautomers are considered. Their oxygen balance values are slightly less than the respective value of FOX-7. Structure-I having a five membered ring system is more stable than structure-II which has a sixmembered ring. Structure-I has lower HOMO energy than II but the reverse is true for the LUMO energies. Consequently, the interfrontier molecular orbital gap is narrower for II compared to I. Then, the later one is expected to be more sensitive to impact stimulus. On the other hand, tautomer IIa is more stable than structure-II: So it is expected to accompany structure-II in various concentrations depending on the conditions.

On the other hand, BDE calculations have revealed that $\mathrm{C}-\mathrm{NO}_{2}$ bond in FOX-7 is more stable than the others (and C-NO${ }_{2}$ bond in structure-I is more stable than it is in structure-II). So, five or six-membered ring building across the $\mathrm{NH}_{2}$ groups of FOX-7 results completely different isomeric structures in terms of stability and energy, thus very different behavioral aspects emerge.

\section{References}

[1] J.P. Agrawal, High Energy Materials, Weinheim: Wiley-VCH, 2010.

[2] P. Politzer and J.S Murray, Energetic Materials, Part 1, Amsterdam: Elsevier, 2003.

[3] I.J. Lochert, FOX-7 - A New Insensitive Explosive, FOX-7, DSTO Aeronautical and Maritime Research Laboratory 506 Lorimer St, Fishermans Bend, Victoria 3207 Australia 2001, AR-012-065, November 2001.

[4] N.V. Latypov, J. Bergman, A. Langlet, U. Wellmar and U. Bemm, Synthesis and reactions of 1,1-diamino-2,2-dinitroethylene, Tetrahedron 54 (1998), 11525-11536.

[5] U. Bemm and H. Östmark, 1,1-Diamino-2,2-dinitroethylene: A novel energetic material with infinite layers in two dimensions, Acta Crystallogr. C54 (1998), 1997-1999.

[6] N.V. Latypov, A. Langlet and U. Wellmar, New chemical compound suitable for use as an explosive, intermediate and method for preparing the compound, Patent WO99/03818; 1999.

[7] H. Östmark, H. Bergman, U. Bemm, P. Goede, E. Holmgren, M. Johansson, A. Langlet, N.V. Latypov, A. Petterson, M.L. Petterson, N. Wingborg, C. Vörde, H. Stenmark, L. 
Karlsson and M. Hihkiö, 2,2-Dinitro-ethene-1,1-diamine (FOX-7) - Properties, analysis and scale-up, 32nd International Annual Conference of ICT on Energetic MaterialsIgnition, Combustion and Detonation, Karlsruhe, Germany, 2001.

[8] H. Östmark, A. Langlet, H. Bergman, N. Wingborg, U. Wellmar and U. Bemm, FOX-7 A new explosive with low sensitivity and high performance, The 11th International Detonation Symposium, Colorado, USA, 1998.

[9] H. Bergman, H. Ostmark, A. Pettersson, M.L. Petterson, U. Bemm and M. Hihkio, Some initial properties and thermal stability of FOX-7, Insensitive Munitions and Energetic Materials Symposium (NDIA), Tampa, Florida, USA, 1999.

[10] W.A. Trzciński and A. Belaada, 1,1-Diamino-2,2-dinitroethene (DADNE, FOX-7) Properties and formulations (a Review), Cent. Eur. J. Energ. Mater. 13(2) (2016), 527544.

[11] B. Janzon, H. Bergman, C. Eldsater, C. Lamnevik and H. Ostmark, FOX-7 - A novel, high performance, low vulnerability high explosive for warhead applications, 20th Int. Symp. Ballistics, Orlando, Florida, USA, September 23-27, 2002.

[12] Y.N. Matyushin, G.T. Afanas'ev, V.P. Lebedev, M.N. Mahov and V.I. Pepekin, TATB and FOX-7: Thermochemistry, performance, detonability, sensitivity, 34th Int. Annu. Conf. ICT, Karlsruhe, Germany, June 24-27, 2003.

[13] A.J. Bellamy, N.V. Latypov and P. Goede, Studies on the nitration of new potential precursors for FOX-7, New Trends Res. Energ. Mater. Proc. Semin. 7th, Pardubice, Czech Republic, April 20-22, 2004.

[14] S. Cudziło, Z. Chyłek and R. Diduszko, Crystallization and characterization of 1,1diamino- 2,2-dinitroethene (DADNE), 36th Int. Annu. Conf. ICT, Karlsruhe, Germany. June 28-July 1, 2005.

[15] W.A. Trzciński, S. Cudziło, Z. Chyłek and L. Szymańczyk, Investigation of sensitivity and detonation properties of FOX-7, 37th Int. Annu. Conf. ICT, Karlsruhe, Germany: June 27-30, 2006.

[16] M. Anniyappan, M.B. Talawar, G.M. Gore, S.Venugopalan and B.R. Ganghe, Synthesis, characterization and thermolysis of 1,1-diamino-2,2-dinitroethylene (FOX-7) and its salts, J. Hazard. Mater. B137 (2006) 8, 12-819.

[17] W.A. Trzciński, S. Cudziło, Z. Chyłek and L. Szymańczyk, Detonation properties of 1,1diamino-2,2-dinitroethene (DADNE), J. Hazard. Mater. 157 (2008), 605-612.

[18] V.S. Mishra, S.R. Vadali, R.K. Garg, V.S. Joshi, R.D. Wasnik and S. Asthana, Studies on 
FOX-7 based melt cast high explosive formulations, Cent. Eur. J. Energ. Mater. 10(4) (2013), 569-580.

[19] N.V. Latypov, M. Johansson, E. Holmgren, E.V. Sizova, V.V. Sizov and A.J. Bellamy, On the synthesis of 1,1-diamino-2,2-dinitroethene (FOX-7) by nitration of 4,6-dihydroxy2-methylpyrimidine, Org. Process Res. Dev. 11(1) (2007), 56-59. doi:10.1021/op068010t

[20] T.M. Klapötke, Chemistry of High-Energy Materials, Berlin: De Gruyter, 2011.

[21] Y. Zhang, Q. Sun, K. Xu, J. Song and F. Zhao, Review on the reactivity of 1,1-diamino2,2-dinitroethylene (FOX-7), Propellants Explos. Pyrotech. 41 (2016), 35-52.

[22] K. Baum, N.V. Nguyen, R. Gilardi, J.L. Flippen-Anderson and C. George, Nitration of 1,1-diamino-2,2-dinitroethylenes, J. Organic Chemistry 57 (1992), 3026-3030.

[23] J. Evers, T.M. Klapötke, F. Mayer, G. Oehlinger and J. Welch, $\alpha$ - and $\gamma$-FOX-7 polymorphs of a high energy density material, studied by X-ray single crystal and powder investigations in the temperature range from 200 to 423 K, Inorg. Chem. 45 (2006), 49965007.

[24] M.J. Crawford, J. Evers, M. Göbel, T.M. Klapötke, P. Mayer, G. Oehlinger and J.M. Welch, $\gamma$-FOX-7: Structure of a high energy density material immediately prior to decomposition, Propellants Explos. Pyrotech. 32 (2007), 478-495.

[25] A. Gindulytė, L. Massa, L. Huang and J. Karle, Proposed mechanism of 1,1-diaminodinitroethylene decomposition: a density functional theory study, J. Phys. Chem. 103 (1999), 11045-11051.

[26] Z.A. Dreger, A.I. Stash, Yu Z.G. Stash, Y.S. Chen, Y. Tao and Y.M. Gupta, Highpressure crystal structures of an insensitive energetic crystal: 1,1-diamino-2,2dinitroethene, J. Phys. Chem. C 120(2) (2016), 1218-1224. doi:10.1021/acs.jpcc.5b10644.

[27] H. Lips and K. Menke, FOX-7/GAP rocket propellants for a shoulder launched projectile, 27th International Symposium on Ballistics, Freiburg, Germany, April 22-26, 2013.

[28] S. Karlsson, H. Östmark, C. Eldsäter, T. Carlsson, H. Bergman, S. Wallin and A. Pettersson, Detonation and Sensitivity Properties of FOX-7 and Formulations Containing FOX-7, FOI Swedish Defence Research Agency, Grindsjöns Research Center, SE-147 25, Tumba, Sweden, 2002.

[29] H. Dorsett, Computational Studies of FOX-7, A New Insensitive Explosive, Published by DSTO Aeronautical and Maritime Research Laboratory PO Box 1500 Salisbury South Australia 5108 Australia, Commonwealth of Australia 2000 AR-011-596, September 2000 . 
[30] L. Türker and S. Varıs, Effects of epoxidation and nitration on ballistic properties of FOX-7, Z. Anorg. Allg. Chem. (ZAAC) 639 (2013), 982-987.

[31] X. Fang and W.G. McLuckie, Laser ignitibility of insensitive secondary explosive 1,1diamino-2,2-dinitroethene (FOX-7), J. Hazard. Mater. 285(21) (2015), 375-82. doi:10.1016/j.jhazmat.2014.12.006.

[32] T. Zhou, Y. Li, K. Xu, J. Song and F. Zhao, The new role of 1,1-diamino-2,2dinitroethylene (FOX-7): two unexpected reactions, New Journal of Chemistry 1 (2017). https://doi.org/10.1039/c6nj03370a

[33] H. Gao and J.M. Shreeve, Recent progress in taming FOX-7 (1,1-diamino-2,2dinitroethene), RSC Advances 1 (2016). https://doi.org/10.1039/c6ra12412g

[34] J.J.P. Stewart, Optimization of parameters for semiempirical methods I. Method, J. Comput. Chem. 10 (1989), 209-220.

[35] J.J.P. Stewart, Optimization of parameters for semi empirical methods II. Application, $J$. Comput. Chem. 10 (1989), 221-264.

[36] A.R. Leach, Molecular Modeling, Essex: Longman, 1997.

[37] P. Fletcher, Practical Methods of Optimization, New York: Wiley, 1990.

[38] W. Kohn and L. Sham, Self-consistent equations including exchange and correlation Effects, J. Phys. Rev. 140 (1965), 1133-1138.

[39] R.G. Parr and W. Yang, Density Functional Theory of Atoms and Molecules, London: Oxford University Press, 1989.

[40] Y. Minenkov, A. Singstad, G. Occhipinti and V.R. Jensen, The accuracy of DFToptimized geometries of functional transition metal compounds: a validation study of catalysts for olefin metathesis and other reactions in the homogeneous phase, Dalton Trans. 41(18) (2012), 5526-41. doi:10.1039/c2dt12232d

[41] K. Sebastian and J.M.L. Martin, Halogen bonds: Benchmarks and theoretical analysis, $J$. Chem. Theory Comput. 9 (2013), 1918-1931. doi:10.1021/ct301064t

[42] A.D. Becke, Density-functional exchange-energy approximation with correct asymptotic Behavior, Phys. Rev. A 38 (1988), 3098-3100.

[43] S.H. Vosko, L. Vilk and M. Nusair, Accurate spin-dependent electron liquid correlation energies for local spin density calculations: a critical analysis, Can. J. Phys. 58 (1980), 1200-1211.

[44] C. Lee, W. Yang and R.G. Parr, Development of the Colle-Salvetti correlation-energy formula into a functional of the electron density, Phys. Rev. B 37 (1988), 785-789. 
[45] SPARTAN 06, Wavefunction Inc., Irvine CA, USA, 2006.

[46] P. Atkins and J. Paula de, Physical Chemistry, 7th ed., p.45, Oxford: Oxford University Press, 2002.

[47] T. Luty, P. Ordon and C.L. Eckhardt, A model for mechanochemical transformations: Applications to molecular hardness, instabilities, and shock initiation of Reaction, $J$. Chem. Phys. 117 (2002), 1775-1785.

[48] H. Zhou, Z.1. Ma, J.1. Wang and D. Wang, Theoretical study of an energetic material di1H-1,3,4-triazole derivatives, Defence Technology 10 (2014), 384-392.

[49] X.J. Xu, W.H. Zhu and H.M. Xiao, DFT studies on the four polymorphs of crystalline CL-20 and the influences of hydrostatic pressure on epsilon CL-20 crystal, J. Phys. Chem. B 111(8) (2007), 2090-7.

[50] P. Ravi, S.K. Shee, G.M. Gore, S.P. Tewari and A.K. Sikder, Quantum chemical investigation on the structure-property relationship of aminopolynitrotriazoles, Strct. Chem. 22 (2011), 661-669.

[51] N.R. Badders, C. Wei, A.A. Aldeeb, W.J. Rogers and M.S. Mannan, Predicting the impact sensitivities of polynitro compounds using quantum chemical descriptors, $J$. Energetic Materials 24 (2006), 17-33.

[52] J.S. Murray, M.C. Concha and P. Politzer, Links between surface electrostatic potentials of energetic molecules, impact sensitivities and $\mathrm{C}-\mathrm{NO}_{2} / \mathrm{N}-\mathrm{NO}_{2}$ bond dissociation energies, Mol. Phys. 107 (2009), 89-97.

[53] F.J. Owens. Calculation of energy barriers for bond rupture in some energetic molecules, J. Mol Struct. (Theochem) 370 (1996), 11-16.

[54] P. Politzer and J.S. Murray, Relationships between dissociation energies and electrostatic potentials of $\mathrm{C}_{-} \mathrm{NO}_{2}$ bonds: applications to impact sensitivities, J. Mol. Struct. (Theochem) 376 (1996), 419-424.

[55] P. Politzer and P. Lane, Comparison of density functional calculations of C-NO $\mathrm{NO}_{2}, \mathrm{NO}_{2}$ and C-NF 2 dissociation energies, J. Mol. Struct. (Theochem) 388 (1996), 51-55.

[56] N.J. Harris and K. Lammertsma, Ab initio density functional computations of conformations and bond dissociation energies for hexahydro-1,3,5-trinitro-1,3,5-triazine, J. Am. Chem. Soc. 119 (1997), 6583-6589.

[57] G.F. Adams, Jr. and R.W. Shaw, Chemical reactions in energetic materials, Annu. Rev. Phys. Chem. 43 (1992), 311-340.

[58] X. Zhao, E.J. Hintsa and Y.T. Lee, Infrared multiphoton of RDX in a molecular beam, $J$. Chem. Phys. 88 (1988), 801-810. 
[59] C.C. Chambers and D.L. Thompson, Further studies of the classical dynamics of the unimolecular dissociation of RDX, J. Phys. Chem. 99 (1995), 15881-15889.

[60] T.R. Botcher and C.A. Wight, Explosive thermal decomposition mechanism of RDX, $J$. Phys. Chem. 98 (1994), 5441-5444.

[61] J.C. Oxley, A.B. Kooh, R. Szekeres and W. Zheng, Mechanisms of nitramine thermolysis, J. Phys. Chem. 98 (1994), 7004-7008.

[62] I. Levin, Quantum Chemistry, New Jersey: Prentice-Hall, 2000.

[63] B.M. Rice, S. Sahu and F.J. Owens, Density functional calculation of bond dissociation energies for $\mathrm{NO}_{2}$ scission in some nitroaromatic molecules, J. Mol. Struct. (Theochem) 583 (2002), 69-72.

[64] J. Shao, X. Cheng and X. Yang, Density functional calculations of bond dissociation energies for removal of the nitrogen dioxide moiety in some nitroaromatic molecules, $J$. Mol. Struct. (Theochem) 755 (2005), 127-130.

[65] D.C. Young, Computational Chemistry: A Practical Guide for Applying Techniques to Real World Problems, New York: John Wiley \& Sons, Inc., 2001. 